\title{
External and middle ear diseases: radiological diagnosis based on clinical signs and symptoms
}

\author{
Agnieszka Trojanowska • Andrzej Drop • \\ Piotr Trojanowski • Katarzyna Rosińska-Bogusiewicz • \\ Janusz Klatka • Barbara Bobek-Billewicz
}

Received: 10 May 2010/Revised: 4 September 2011 /Accepted: 9 September 2011 /Published online: 15 October 2011

(C) The Author(s) 2011. This article is published with open access at Springerlink.com

\begin{abstract}
Objective Pathology of the external and middle ear is the most frequent reason to prescribe antibiotics and perform surgery in children and young adults. In the majority of cases imaging studies are not performed; the need for imaging comes when complications are suspected or when treatment is not effective. This paper discusses indications for temporal bone imaging studies and presents the most frequent pathological conditions, together with differential diagnosis, clinical symptoms and methods of treatment.

Methods and Results This pictorial review describes major external and middle ear diseases, with special regard to clinical findings and appropriate reporting.

Conclusions Apprehension of the complete clinical picture, together with imaging clues, narrows differential diagnosis and helps avoid mistakes. Evaluation of temporal bone
\end{abstract}

\footnotetext{
A. Trojanowska $(\bowtie)$

Department of Diagnostic Radiology,

Medical University of Lublin,

ul. Ogrodowa 15,

20-075 Lublin, Poland

e-mail: agnieszka30@yahoo.com

P. Trojanowski $\cdot$ J. Klatka

Department of Head and Neck Surgery,

Medical University of Lublin,

Lublin, Poland

B. Bobek-Billewicz

Department of Radiology, Maria Sklodowska-Curie Memorial Cancer Center and Institute of Oncology, Gliwice Branch,

Gliwice, Poland

\section{A. Drop $\cdot$ K. Rosińska-Bogusiewicz}

Department of Diagnostic Radiology and Nuclear Medicine,

Medical University of Lublin,

ul. Jaczewskiego 8,

20-950 Lublin, Poland
}

pathologies requires close cooperation between the clinician and radiologist.

Keywords External ear - Middle ear - Disease - Diagnosis · CT $\cdot$ MRI

\section{Introduction}

Pathology of the external and middle ear is the third most common reason of visiting a general practitioner or a family doctor $[1,2]$. In children and teenagers, inflammatory conditions of the middle ear are the most frequent reasons to prescribe antibiotics and perform surgery [3].

In the majority of these cases, proper diagnosis is made by clinical examination alone and patients will not benefit from additional diagnostic imaging studies. However, the prevalence of ear infections increased significantly between 1980 and 1996, and this may suggest that the current approach to preventing and treating middle ear inflammation is not adequate [2, 3]. Therefore, especially in complicated and recurrent conditions, imaging plays an important role; imaging findings may fundamentally influence the treatment [4]. Also, in non-inflammatory conditions of external and middle ear computed tomography (CT) or magnetic resonance imaging (MRI) would provide a diagnosis and/or necessary information for surgery in a significant number of cases $[5,6,9]$.

Usually, patients with temporal bone pathology first undergo clinical examination, often with audiology tests. Information obtained this way, when combined with imaging findings, provides an accurate and trustworthy diagnosis, allows avoiding misinterpretation and ensures appropriate treatment. 


\section{External ear}

The external ear is accessible to direct evaluation and indications for imaging are limited. Among the most important ones are:

\section{External auditory canal (EAC) atresia}

Definition Absence of external ear canal being a birth defect, and accompanied by auricle malformation.

Symptoms Conductive hearing loss. On clinical examination, usually the auricle is malformed (microtia) and the EAC is not patent or significantly narrowed. In such ears the sound cannot reach the tympanic membrane; this is why conductive hearing loss results.

Preferable imaging method High-resolution CT (HRCT) of the temporal bone is the method of choice. Since atretic external auditory canal does not allow visualization of tympanic membrane and middle ear structures, imaging studies are mandatory [7].

Clinically relevant imaging findings Radiological findings are critical for accurate classification of the severity of disease and surgical decision-making. For selection of best surgical candidates, images should be evaluated according to the grading system proposed by Jahrsdorfer et al. [9], who evaluated eight critical areas of temporal bone anatomy, each area receiving 1 rating scale point, with the exception of the presence of a stapes, which received 2 points (Table 1). Patients with a pre-surgical rating of $\leq 5$ points should not be considered surgical candidates. A presurgical rating of 8 points translates into an $80 \%$ chance of resorting hearing to normal or near-normal levels.

Often the malformation involves ossicles and middle ear space to varying degrees. The inner ear is most often normal [8]. Among frequently observed middle ear devel-

Table 1 The preoperative evaluation of congenital aural atresia based on high-resolution CT findings, as proposed by Jahrsdorfer et al. [9]

\begin{tabular}{ll}
\hline Structure & Points \\
\hline Stapes present & 2 \\
Oval window open & 1 \\
Middle ear space & 1 \\
Facial nerve & 1 \\
Malleus/incus complex & 1 \\
Mastoid pneumatised & 1 \\
Incus-stapes connection & 1 \\
Round window & 1 \\
Appearance external ear & 1 \\
\hline
\end{tabular}

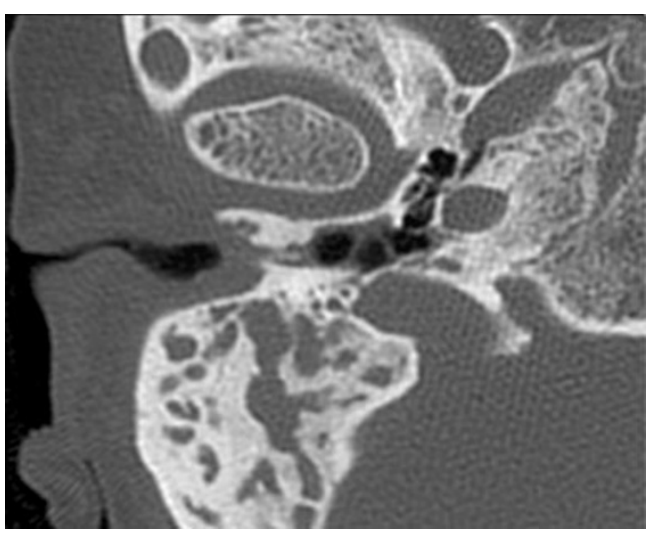

Fig. 1 Congenital external ear malformation. Axial CT scan shows significantly narrowed EAC with soft tissue and bone obliteration

opmental anomalies are: hypoplastic middle ear cavity (Fig. 1), deformed ossicles (Fig. 2), oval window atresia, aberrant course of the facial nerve, absent or hypoplastic tympanic bone (Fig. 3).

Differential diagnosis Acquired EAC stenosis (surfer's ear), EAC osteoma, EAC cholesteatoma.

Treatment options if the other ear is functioning well, unilateral atresia is not treated. Bilateral atresia is treated surgically at the age of 5-6 years. Usually middle ear surgery is preceded by auricle reconstruction. It is unnecessary to perform CT examination in early childhood, before the middle ear grows to almost-adult size. Unilateral atresia is also effectively managed with a Baha-a surgically implantable system which works through direct bone conduction.

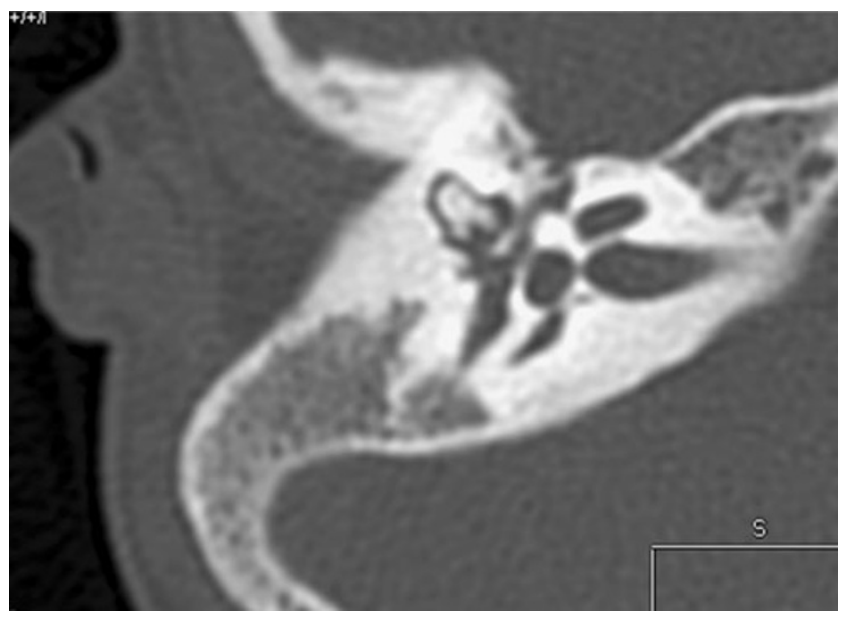

Fig. 2 Congenital external ear malformation. Axial CT scan, bone window. Deformed ossicular chain is visible within hypoplastic tympanic cavity. Proper malleus and incus together with malleoincudal joint can not be identified, instead, there is a V-shaped bony structure, representing the fused malleo-incudal complex 


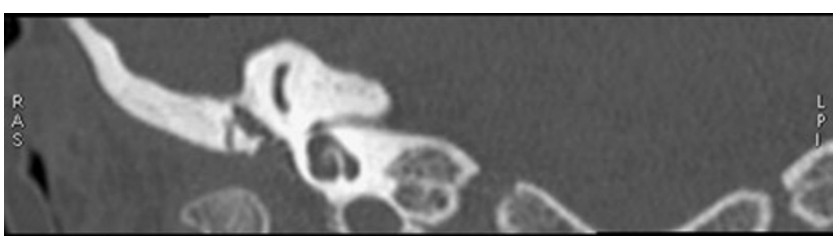

Fig. 3 Severe external and middle ear deformity accompanying Goldenhar syndrome (oculoauricular dysplasia). Coronal CT scan shows, that tympanic bone, forming the floor of EAC is absent. It also results in temporomandibular joint incomplete formation

\section{Necrotizing external otitis}

Definition Infection involving primarily bony and cartilaginous external auditory canal and adjacent structures, being a relatively rare complication of external otitis. It occurs usually in immunocompromised persons, especially elderly patients with diabetes mellitus, and is often initiated by selfinflicted or iatrogenic trauma to the external auditory canal [10].

Symptoms Clinically, patients complain of severe otalgia that worsens at night, and otorrhea. Otoscopic findings include granulation tissue in the external auditory canal, particularly at the bony-cartilaginous junction. On audiology there is conductive hearing loss [11].

Preferable imaging methods Imaging modalities include CT and MRI. While CT scanning allows to determine the location and extent of disease, MRI is the method of choice in determining intracranial extension. Since malignant external otitis has potentially life-threatening complications, imaging studies are strongly advised [11].

Clinically relevant imaging findings Thickened mucosa of the external auditory canal and auricle, enhancing after contrast

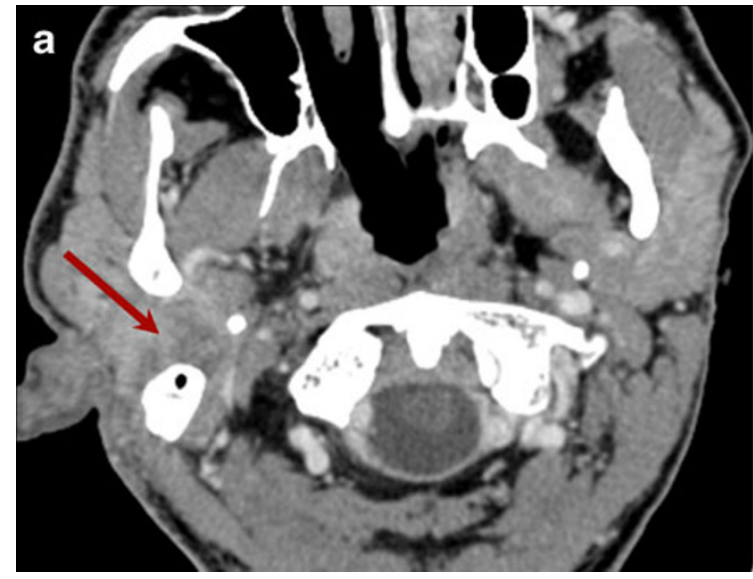

Fig. 4 Malignant external otitis. a Axial contrast enhanced CT scan shows thickening and heterogenous contrast enhancement of the soft tissue around auricle and in masticator space (arrow). b In the bone

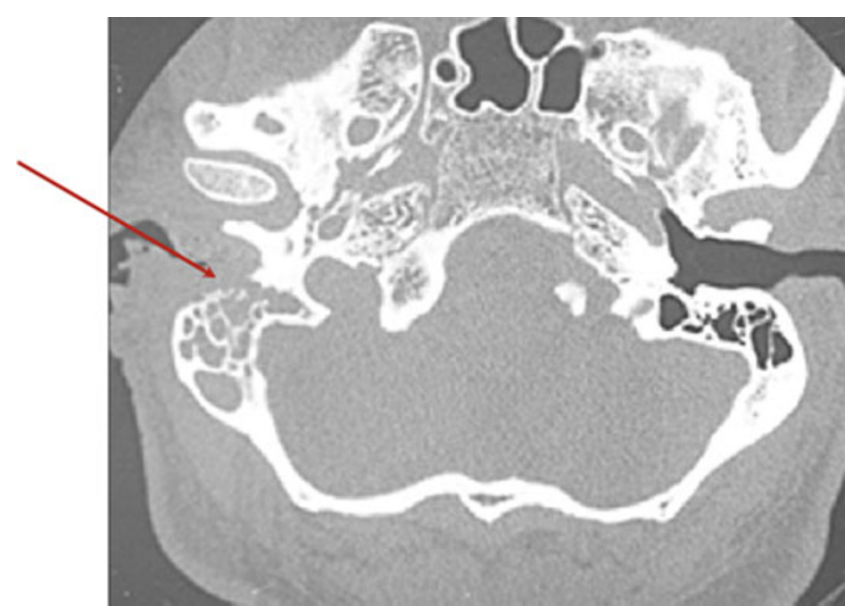

Fig. 5 Malignant external otitis. Axial CT scan in bone window demonstrates destruction of mastoid segment of petrous bone. There were also subtle cortical destructions visible in tympanic bone

medium administration (Fig. 4), together with destructive, osteomyelitis appearance of the tympanic and mastoid bone (Fig. 5), strongly suggest malignant external otitis. Subtle cortical erosions visible on $\mathrm{CT}$ are usually an early sign of evolving osteomyelitis, as well as infiltration of the temporomandibular fat pad [12]. Meningeal enhancement, visible on MRI informs about intracranial extension. Focal areas of rim-enhancing fluid visible in adjacent soft tissues are consistent with abscesses. Absolutely critical is posteromedial extension to the jugular foramen or carotid space.

Differential diagnosis Includes EAC cholesteatoma, postinflammatory medial canal fibrosis, keratosis obturans and EAC squamous cell cancer.

Note: it may be very difficult to differentiate between EAC cholesteatoma and malignant external otitis, because

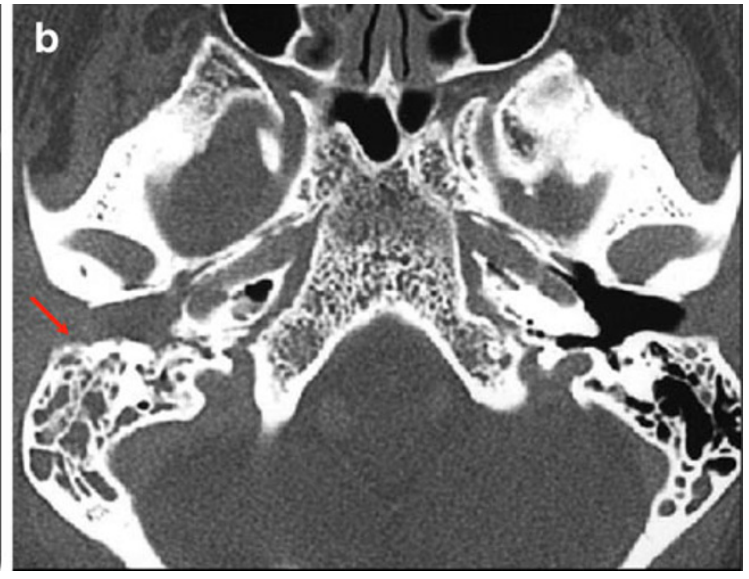

window, subtle bone erosion is visible (arrow) and mastoid air cells are filled with fluid 
of the same pattern of bony invasion and soft tissue mass. Attention should be paid to clinical history $[6,12]$.

Treatment options Surgical debridement of visible granulation plus systemic antibiotic therapy. Drainage of abscesses.

\section{EAC Exostoses}

Definition benign-appearing bony protuberances, arising from the osseous portions of EAC. They are found commonly in people with prolonged, repetitive exposure to cold water ("surfer's ear") $[6,13]$.

Symptoms conductive hearing loss and recurrent episodes of external otitis with otalgia.

Preferable imaging method HRCT of the temporal bone is the examination of choice; intravenous contrast is not required to make the diagnosis.

Clinically relevant imaging findings exostoses are typically seen as benign bony overgrowth with normal overlying soft tissue, always bilateral, and located close to the tympanic annulus at the tympanomastoid and tympanosquamous sutures (Fig. 6) [13, 14]. The lumen of the EAC may be significantly narrowed (Fig. 7).

Differential diagnosis Includes: radiologically, EAC osteoma; clinically, medial canal fibrosis, necrotizing external otitis and EAC cholesteatoma. On imaging, the last three entities are visible as soft tissue lesions with or without bone destruction. A history of cold water and wind exposure facilitates the diagnosis [13].

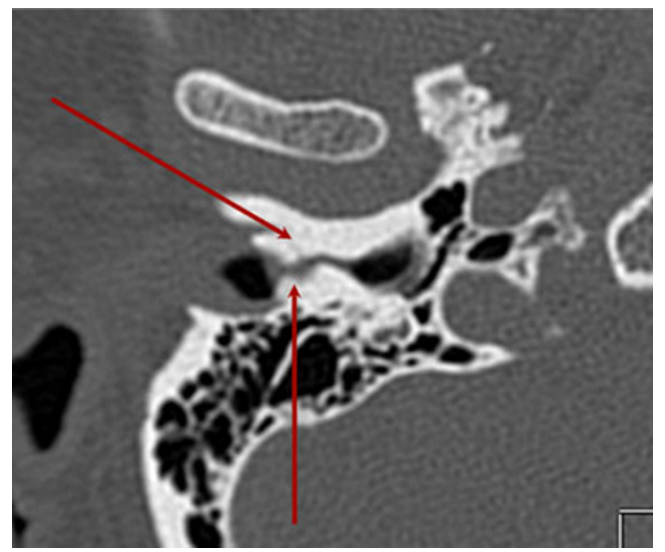

Fig. 6 Surfer's ear. Axial CT scan demonstrates broad-based overgrowth of osseous EAC (arrows)

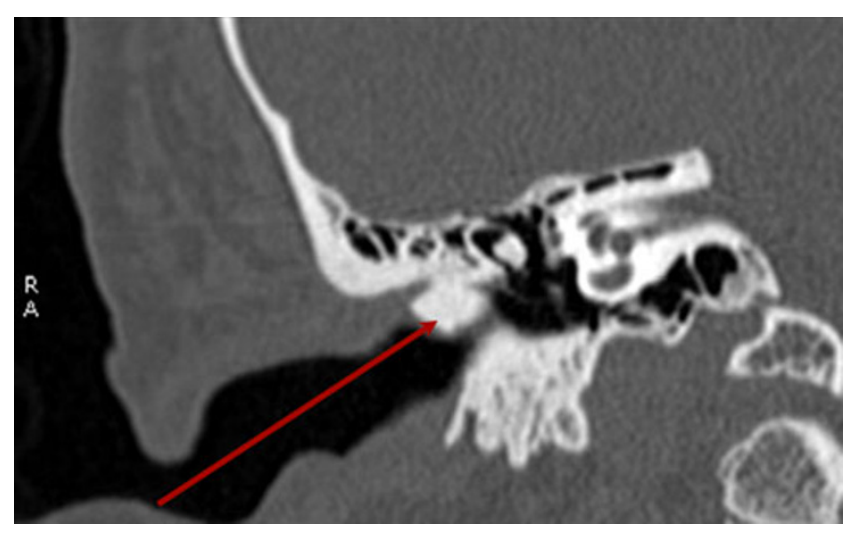

Fig. 7 Surfer's ear. Coronal CT scan shows benign appearing bone expansion, significantly narrowing EAC (arrow)

Treatment options Usually require no treatment, sometimes may require surgical excision.

\section{EAC medial canal fibrosis}

Definition post-inflammatory, acquired atresia of EAC. The disease is characterised by formation of fibrous tissue, overlying lateral surface of tympanic membrane. In many cases $(\sim 60 \%)$ it occurs bilaterally $[4,6]$.

Symptoms Clinically the disease may be discrete, with conductive hearing loss, otorrhea and history of chronic otitis.

Preferable imaging method Temporal bone HRCT is the examination of choice.

Clinically relevant imaging findings medial canal fibrosis typically is seen as a homogenous soft tissue against the tympanic membrane (Fig. 8a, b), there are no EAC bone changes.

Differential diagnosis This includes keratosis obturans, EAC exostoses, EAC cholesteatoma, necrotizing external otitis, squamous cell carcinoma of EAC.

Treatment options Surgical intervention. At early phase topical antibiotics and steroids may help.

\section{EAC squamous cell carcinoma}

Definition Neoplasm in the EAC. This tumour has an aggressive nature and spreads along vascular and neural pathways, invading adjacent structures [15]. Most squamous cell carcinomas of the temporal bone occur in the 5th and 6th decades of life. 
Fig. 8 EAC medial canal fibrosis. a Coronal CT demonstrates soft tissue crescent abutting tympanic membrane (arrow) classic CT findings. b On axial $\mathrm{CT}$, soft tissue is visible, filling EAC and sparing middle ear cavity
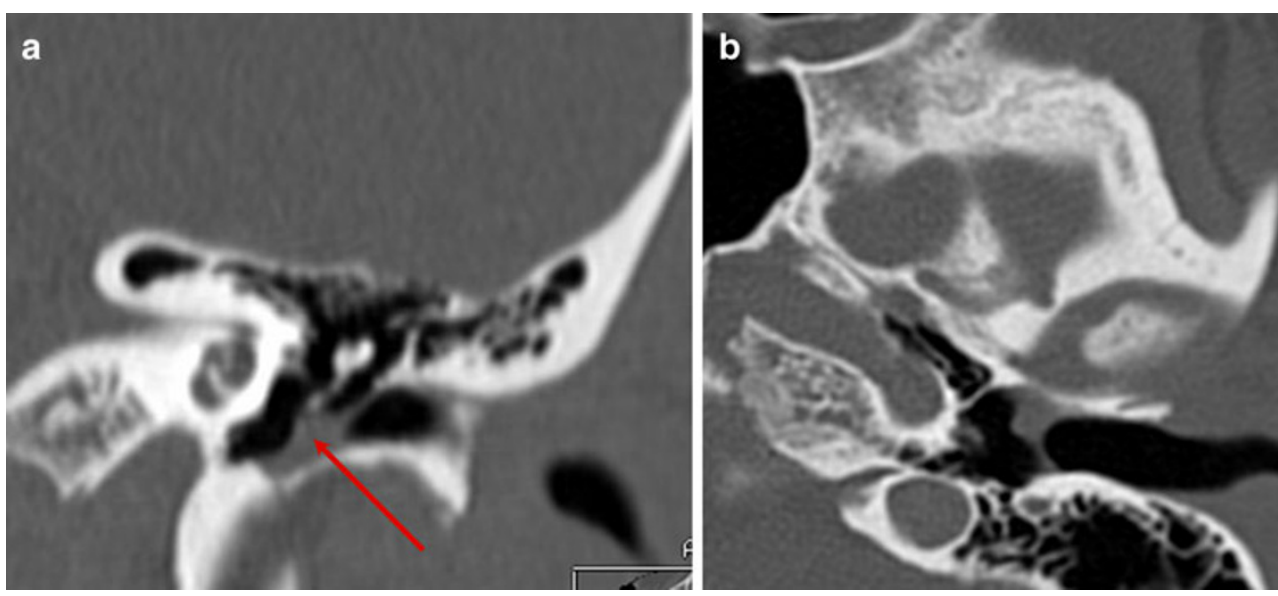

Symptoms These include otorrhea, otalgia, hearing loss and bleeding. Diagnosis is usually delayed because symptoms are similar to other benign otological conditions such as chronic suppurative otitis media or EAC cholesteatoma $[15,16]$.

Preferable imaging methods Temporal bone HRCT best predicts tumour extent in terms of osseous destruction; in larger lesions, enhanced MRI images are necessary to assess soft tissue and intracranial involvement, also perineural spread. Imaging should always include parotid gland, since parotid nodes are a first-order drainage nodal group.

Clinically relevant imaging findings A mass in the EAC, with underlying bony destructive changes (Fig. 9). Very small tumours may not infiltrate bone; they present only as lobular, soft tissue mass. Larger lesions spread around the auricle, infiltrate parotid gland and enhance heterogeneously after contrast (Fig. 10). It should be remembered that bone invasion predicts treatment outcome.

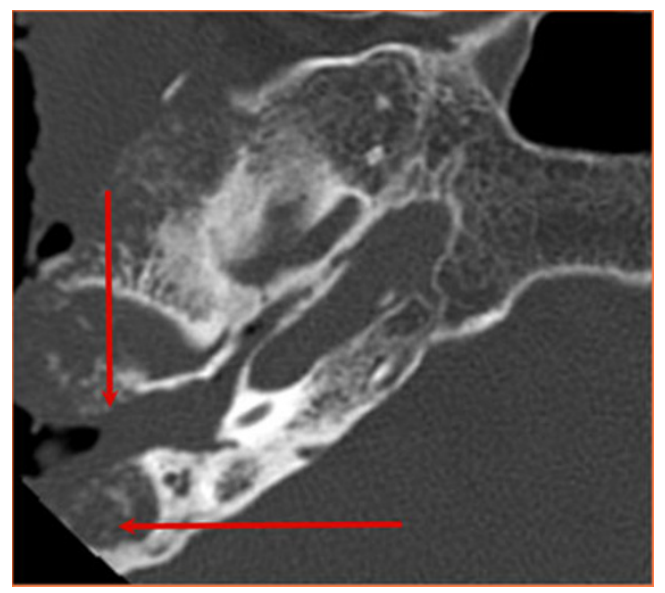

Fig. 9 Squamous cell cancer of EAC. Axial bone-window CT shows mass, invading mastoid air cells with signs of profound bone destruction of mastoid and temporo-mandibular joint
Differential diagnosis This includes medial canal fibrosis, keratosis obturans, necrotizing external otitis and EAC cholesteatoma.

Treatment options These depend on the tumour stage (see Table 2) and are generally based on the combination of surgery and radiotherapy. The extent of disease, positive margins, dural involvement, facial nerve paralysis, cranial nerve involvement, or moderate to severe pain on presentation have been associated with poorer outcomes [16]. When resected with free margins, 5-year survival reaches $100 \%$. With incomplete resection, recurrence rate depends on tumour stage and is reported between 25 to $100 \%$ [8].

Note: secondary EAC involvement from regional primary $\mathrm{SCC}$ is much more common than primary EAC squamous cell cancer.

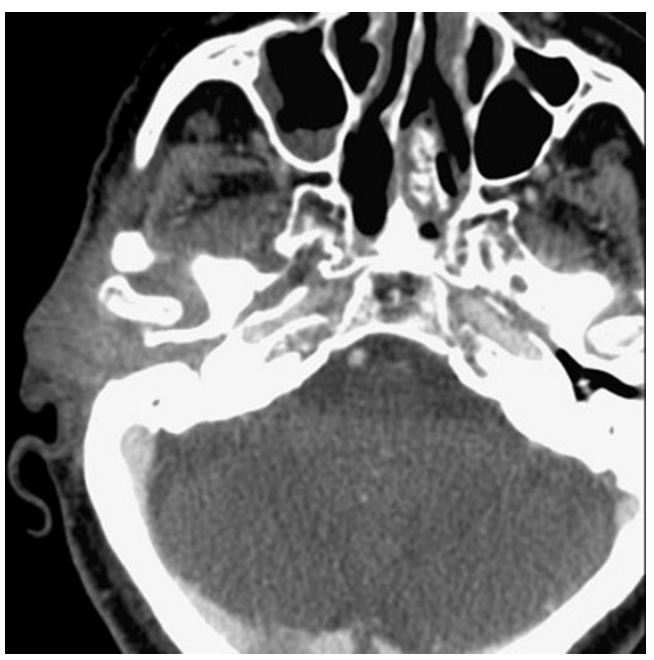

Fig. 10 Squamous cell cancer of EAC. Axial contrast-enhanced CT demonstrates heterogenously enhancing soft tissue mass infiltrating auricle, parotid gland and EAC 
Table 2 Classification criteria (staging) for EAC squamous cell carcinoma

$\begin{array}{ll}\text { T1 } & \text { Tumour limited to EAC without bone erosion and soft tissue involvement } \\ \text { T2 } & \text { Tumour with limited EAC osseous erosion or soft tissue involvement } \\ \text { T3 } & \text { Tumour eroding osseous EAC with limited soft tissue/middle ear/mastoid involvement } \\ \text { T4 } & \text { Tumour eroding deeper inner ear structures/temporomandibular joint/deep soft tissue extension/facial nerve paresis/distant metastases }\end{array}$

\section{Middle ear}

The middle ear is hidden behind the tympanic membrane, what makes direct non-invasive evaluation limited in many cases.

Although the pathology itself can be well estimated on otoscopic examination, further questions concerning the extent of the disease, exact location, structures involved and possible bone erosion, will be addressed in detail only with $\mathrm{CT}$ and/or MRI.

The majority of everyday practice cases will consist of inflammatory diseases, either chronic or acute, and sometimes tumours. On CT examination, these entities will demonstrate a mass, or a diffuse opacification of middle ear cavity [17].

Since an opacified middle ear is a common finding on imaging studies [6], a practical classification has been used, in order to facilitate differential diagnosis (Table 3).

Traumatic opacified middle ear

Trauma to the temporal bone is usually the result of a blunt head injury. Patients with temporal bone fracture may present at the time of trauma with evidence of basilar skull fracture, such as battle sign, raccoon eyes, or hemotympanum. In addition, they may complain of hearing loss or dizziness $[18,19]$. If a temporal bone fracture initially goes unrecognised, delayed presentation may involve cerebrospinal fluid (CSF) otorrhea, hearing loss, or symptoms related to cranial nerve VII dysfunction.

Because the traditional fracture classification system (transverse and longitudinal) may not predict the presence of sequelae, such as facial nerve injury or CSF leak, fractures should be classified, based on whether they are otic capsule sparing or otic capsule violating (Fig. 11a, b) [8]. Also, hearing would be preserved only when the otic capsule is spared $[19,20]$.

HRCT images provide detailed information concerning fractures and their complications.

Opacification visible on imaging studies in the tympanic cavity may represent blood (Fig. 12) or CSF.

On radiological evaluation, special attention should be paid to the following details:

Possible disruption of ossicular chain (see Fig. 12)

Communication of the fracture lines with facial nerve canal (Fig. 13)

Communication of fracture lines with internal ear structures, e.g. cochlea, vestibule, semicircular canalspossible otic capsule involvement (Fig. 14)

Carotid canal injury

Non-traumatic opacified middle ear: Eustachian tube dysfunction (secretory otitis)

Definition Persistent mucoid or serous middle ear effusion, in the absence of acute inflammation [21]. Eustachian tube dysfunction is well known to be related in the pathogenesis of secretory otitis. Secretory otitis is the most common disease in children, sometime it can be seen in adults. In children, this can occur purely from enlarged adenoids, with no pain or bacterial infection. In adults, secretory otitis may be found when a growing tumour in the nasopharynx blocks Eustachian tube opening [22] (Fig. 15a, b).
Table 3 Classification of middle ear opacification according to most frequent causes

\begin{tabular}{lll}
\hline Opacified middle ear & Traumatic & Otic capsule sparing \\
& Otic capsule involving & \\
Non-traumatic & $\begin{array}{l}\text { Eustachian tube dysfunction (secretory otitis) } \\
\text { Acute inflflammation/infection }\end{array}$ & \\
& Chronic inflammation/infection $\quad$ With acquired cholesteatoma \\
& & Without cholesteatoma \\
& Glomus tympanicum & \\
& Middle ear schwannoma & \\
\end{tabular}


Fig. 11 Temporal bone trauma. a Axial bone-window CT scan demonstrates fracture line limited to mastoid (arrow) and not affecting otic capsule structures. b Axial bonewindow CT scan shows fracture with involvement of lateral semicircular canal (arrow) and vestibule. This is a typical otic capsule involving fracture
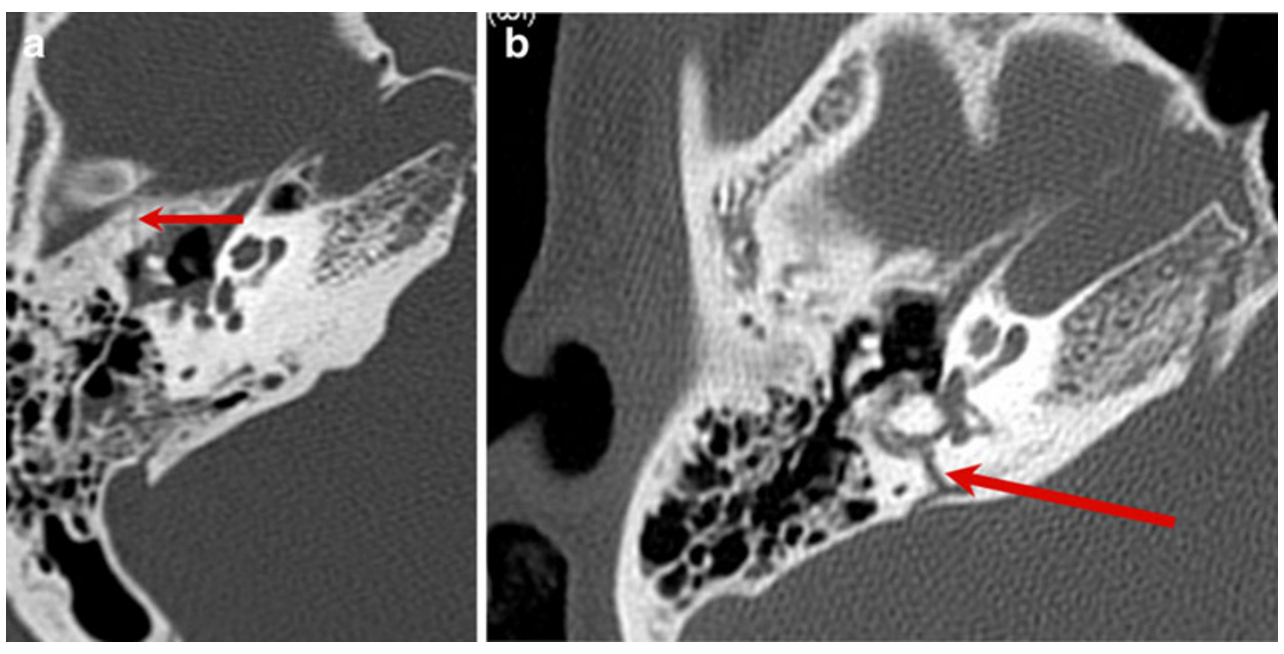

Symptoms Fluid filling the middle ear cavity causes tympanic membrane bulging with no signs of acute infection (redness, pain, oedema). Over time, middle ear fluid can become very thick and glue-like ("glue ear"), which increases the likelihood of conductive hearing loss.

Preferable imaging methods Temporal bone HRCT is the examination of choice; however, when nasopharyngeal pathology is suspected, contrast-enhanced MRI study should be considered. In children, diagnosis is usually made based on tympanometry, therefore CT should not be ordered.

Clinically relevant imaging findings Middle ear cavity and mastoid air cells are completely, homogeneously opacified. There is no ossicular chain erosion (Fig. 16).

Differential diagnosis This includes acute otomastoiditis, acquired cholesteatoma and Langerhans cell histiocytosis.

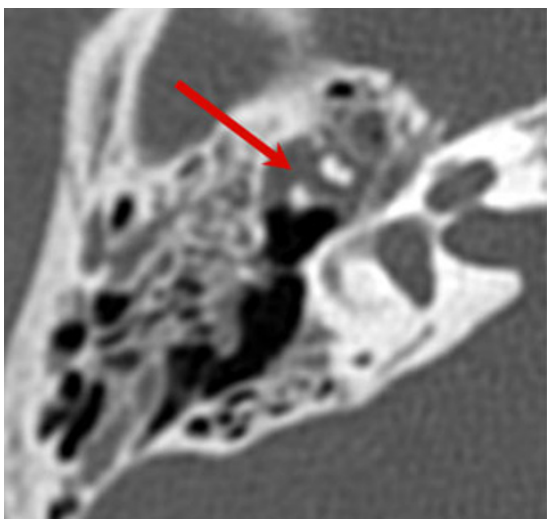

Fig. 12 Temporal bone trauma. Axial bone CT demonstrates opacified middle ear (arrow), clinically visible as haemotympanum. Detachment of malleus from incus is also visible
Non-traumatic opacified middle ear: acute inflammation/ infection

Definition Acute middle ear infection (acute otitis media, acute otomastoiditis) usually presenting with typical clinical image and in most cases not requiring imaging.

Symptoms These include earache, fever, pain, otorrhea, conductive hearing loss. On otoscopy tympanic membrane is red and bulging $[1,2]$.

Both from clinical and radiological points of view, it is important to differentiate between acute otitis media and secretory otitis [21].

Secretory otitis means fluid in the middle ear cavity without signs or symptoms of infection; this is usually caused when the Eustachian tube patency is compromised and fluid is trapped in the middle ear. Signs and symptoms

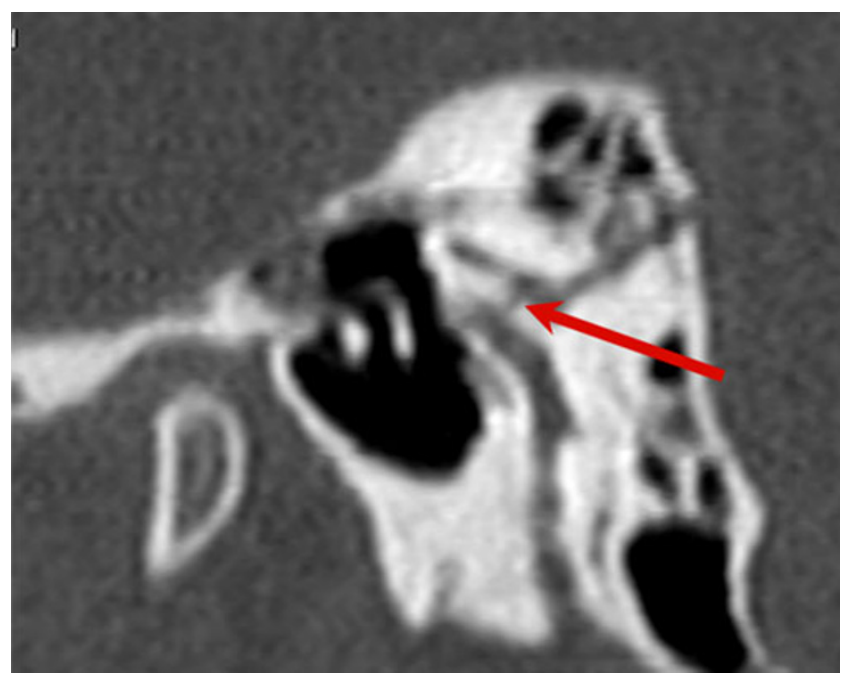

Fig. 13 Temporal bone trauma. Sagittal CT scan illustrates communication of fracture line with facial nerve canal in mastoid segment (arrow) 


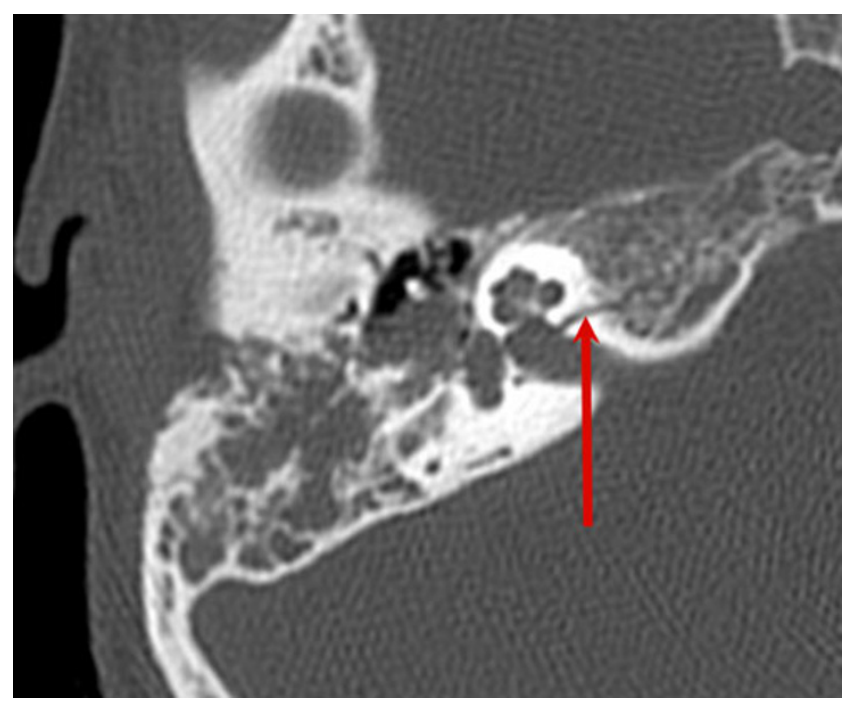

Fig. 14 Temporal bone trauma. Axial CT scan shows fracture line crossing internal auditory canal (arrow). Since the fracture extends through fundus of internal auditory canal, it was associated with complete hearing loss due to cochlear nerve transection

of acute otitis media occur when effusion in the middle ear becomes infected.

Need for imaging usually takes place, if standard treatment fails, and complications occur.

Such complications include acute coalescent otomastoiditis (ACOM). This is an acute infection of middle ear and mastoid air cells, with progressive resorption of mastoid septae [8].

Preferable imaging method Temporal bone HRCT is the modality of choice to evaluate possible ACOM. Erosion of mastoid septations and cortex is the most sensitive and specific finding (Fig. 17). When intracranial complications are suspected, MRI is the examination of choice.

Clinically relevant imaging findings Since in severe cases ACOM may lead to severe complications, like abscess

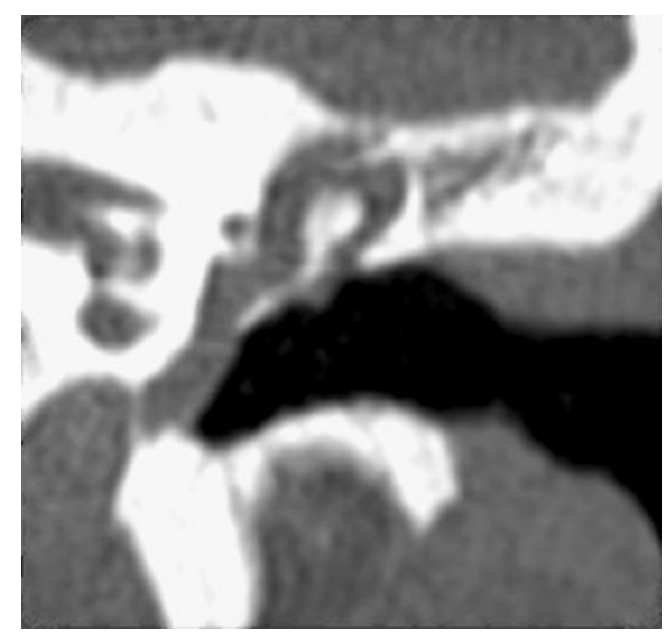

Fig. 16 Secretory otitis. Whole middle ear is homogenously opacified; ossicular chain and walls of tympanic cavity show no signs of destruction

formation and sinus thrombosis, the following structures should be evaluated carefully: labyrinth, meninges, sigmoid sinus, skull base.

Differential diagnosis This includes rhabdomyosarcoma, Langerhans cell histiocytosis, acute uncomplicated otomastoiditis and acquired cholesteatoma.

Treatment options Acute otitis media is usually treated with antibiotics, sometimes myringotomy. With complicated ACOM, surgery and mastoidectomy are usually needed.

Non-traumatic opacified middle ear: chronic inflammation/ infection

Definition When the inflammation persists at least 6 weeks and is associated with otorrhea through a perforated

Fig. 15 Middle ear secretory otitis. a Axial contrastenhanced CT shows a mass filling left nasopharynx and compromising Eustachian tube patency. b Axial CT scan shows that left middle ear cavity and mastoid air cells are completely opacified
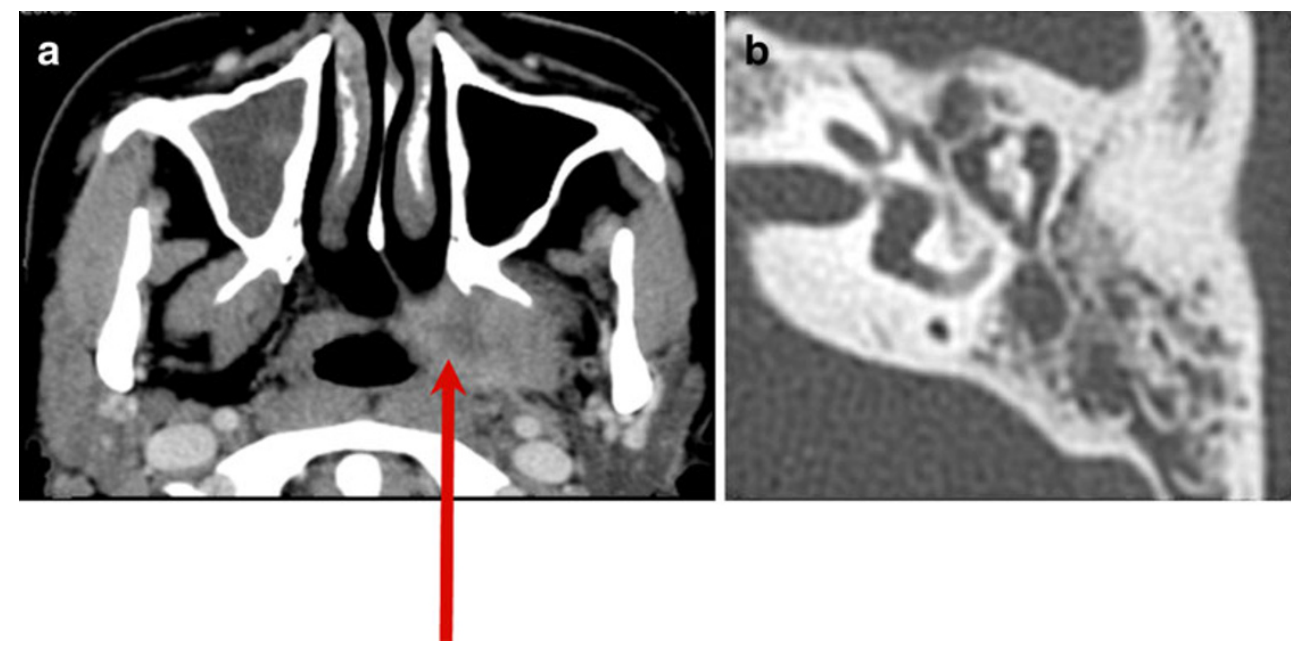


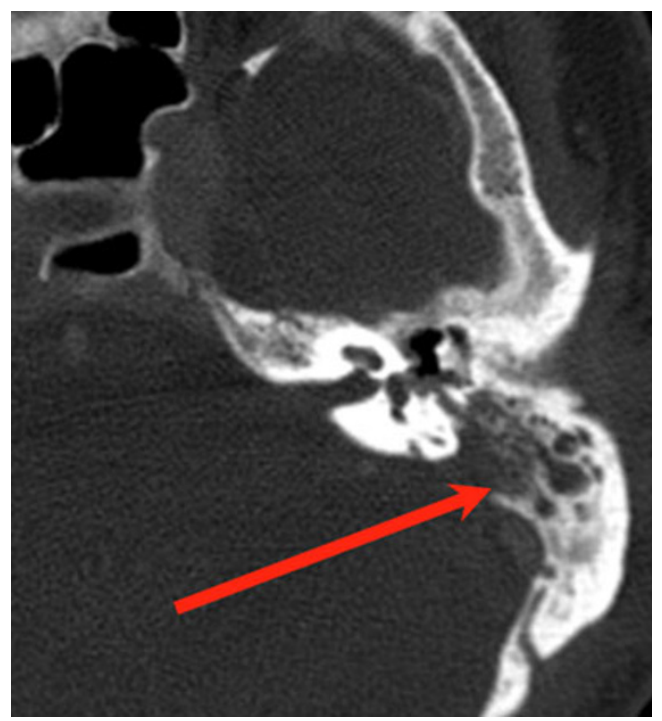

Fig. 17 Acute coalescent otomastoiditis (ACOM). Axial scan in bone window demonstrates diffuse opacification of middle ear and mastoid with destructions of mastoid septations and sigmoid plate (arrow)

tympanic membrane, chronic otitis media (COM) is diagnosed [23].

Symptoms These include conductive hearing loss, sometimes pain, vertigo, otorrhea.

Many patients with COM will undergo diagnostic imaging studies. Among main indications are [17]:

Long-standing inflammation, unresponsive to medical treatment

Evaluation of possible causes of conductive hearing loss (ossicle erosion or fixation)

Clinical suspicion of cholesteatoma

Suspected intratemporal complications, such as petrositis, labyrinthitis, subperiosteal abscess, labyrinthine fistula

Suspected intracranial complications like brain abscess, meningitis

Preferable imaging methods Both CT and MRI are used in the evaluation of COM and its complications. HRCT is the best tool to evaluate ossicular chain and tympanic cavity walls. However, CT is unable to differentiate between different types of effusions in the tympanic cavity, also evaluation of cholesteatoma can be challenging [17, 24]. MRI plays role in the detection of primary and residual cholesteatoma, also when intracranial and some intratemporal complications are suspected.

Since some ears with chronic inflammation develop cholesteatoma, COM may be classified into two groups: with or without cholesteatoma.
Chronic otitis media without cholesteatoma

In the setting of chronic middle ear inflammation, if there is no clinical suspicion of cholesteatoma, imaging studies are performed to evaluate:

Reasons for conductive hearing loss (possible ossicular chain fixation or erosion)

Tympanic cavity walls

Semicircular canals,

Facial nerve canal

Post-inflammatory ossicular chain fixation (PIOF) is a common problem in patients with conductive hearing loss [25]. On CT images, three distinctive forms of PIOF can be evaluated:

Presence of fibrous tissue, usually in the niche of oval window, forming a so-called "peristapedial tent" (Fig. 18). Fibrous tissue may also be present anywhere in mesotympanum and epitympanum.

Tympanosclerosis, which reflects deposits of hyalinised collagen in the tympanic cavity. If it occurs in tympanic membrane, it is called myringosclerosis (Fig. 19). In the tympanic cavity, it may be present in any location, visible as focal calcified densities in the middle ear cavity, along tendons, also in direct apposition to the ossicular chain (Fig. 20).

Formation of new bone, rarely seen in the tympanic cavity, usually in epitympanum. Visible as lamellar structures of high density.

Differential diagnosis of radiological images includes congenital cholesteatoma in the middle ear.

Post-inflammatory ossicular chain erosion is rather rare in case of a non-cholesteatomatous disease, but may seldom occur and will affect first the incus long process and lenticular process, followed by stapes head [17].

For best diagnostic accuracy, images should be viewed in correct bone window setting - large window width (e.g. 4,000 HU) and low window level (e.g. 0-200 HU).

In order to evaluate possible ossicular erosion, axial CT images should be searched for three distinctive signs:

"Ice cream cone" visible in the epitympanum, where the anterior ice cream consists of the malleus head and the posterior cone is made of the incus body and short process (Fig. 21)

"Two parallel lines" visible in the mesotympanum, where the anterior line represents the malleus handle and the posterior line represents the incus long process (Fig. 22)

"Two dots" visible in the mesotympanum, the lateral dot being the lenticular process and the medial dot 
Fig. 18 Chronic middle ear inflammation. a Coronal CT in bone window shows opacification around oval window niche, encasing stapes superstructure (arrow). b Soft tissue around stapes crura is visible on axial slice at the level of oval window. This represents fibrous tissue, which develops in the course in chronic inflammation and may cause conductive hearing loss
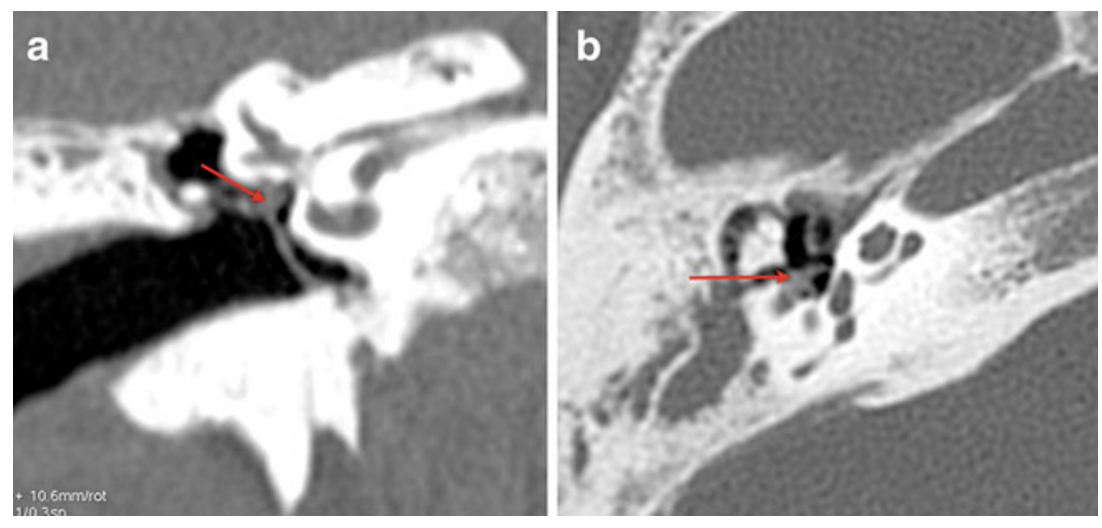

being the stapes head-between them the incudostapedial joint is well visible (Fig. 23)

In cases of post-inflammatory ossicular chain erosion, any or all of three signs will not be visualised on axial CT scans.

Differential diagnosis includes congenital ossicular deformity, cholesteatoma with ossicular erosion, postoperative ossicular loss.

Post-inflammatory erosion sometimes involves walls of tympanic cavity. Based on CT multiplanar images the following structures should first of all be evaluated:

Bony cover of lateral semicircular canal

Bony cover of the second (tympanic) segment of the facial nerve

Roof of the middle ear cavity (tegmen tympani)

Chronic otitis media with acquired cholesteatoma

Definition Cholesteatoma means "skin in the wrong place". It consists of squamous epithelium that is trapped within the middle ear and mastoid [23].

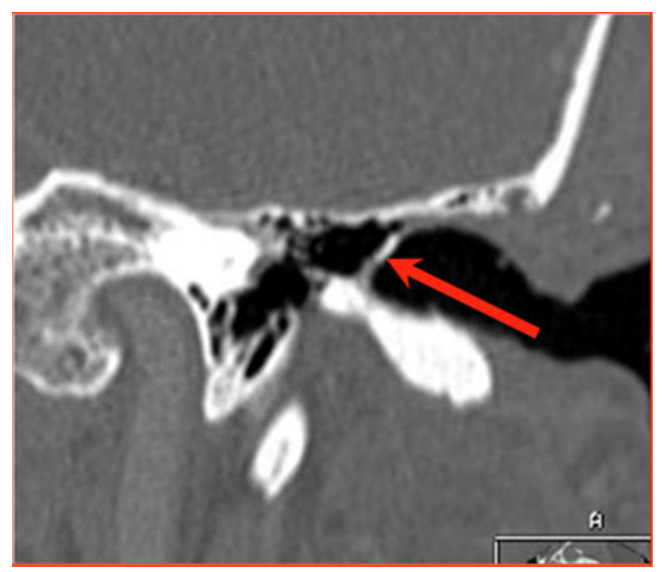

Fig. 19 Chronic middle ear inflammation. Axial CT scan demonstrates focal calcifications in thickened tympanic membrane (arrow). This is called myringosclerosis
In the setting of chronic middle ear inflammation, cholesteatomas arise as the result of tympanic membrane retraction or perforation [24, 25].

The classic acquired cholesteatoma develops from medial retraction of the pars flaccida into the epitympanum (pars flaccida cholesteatoma). As this process continues, the scutum becomes eroded; ossicular destruction is common. If the cholesteatoma invades posteriorly into the aditus ad antrum and the mastoid itself, erosion of the tegmen tympani, with exposure of the dura and/or erosion of the lateral semicircular canal may appear [17] (Fig. 24).

A second, less frequent type of an acquired cholesteatoma arises when the posterior quadrant of the tympanic membrane is retracted into the posterior middle ear (pars tensa cholesteatoma). As retraction continues, squamous epithelium envelops the suprastructure of the stapes and fills in sinus tympani. Cholesteatomas arising from the posterior tympanic membrane are likely to produce facial nerve exposure, eroding bony cover of facial nerve canal, and destruction of the stapedial suprastructure $[26,27]$.

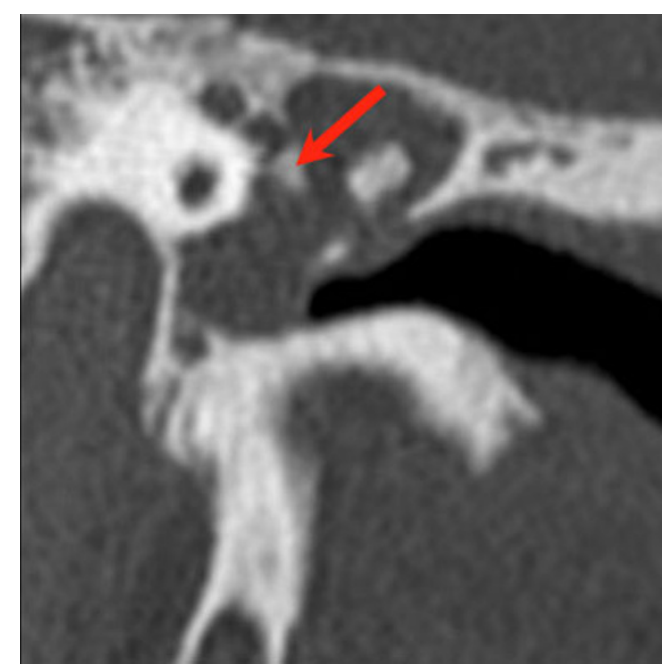

Fig. 20 Chronic middle ear inflammation. Axial CT in bone window demonstrates focal calcifications (arrow) in the tympanic cavity, close to ossicular chain. This is called tympanosclerosis 


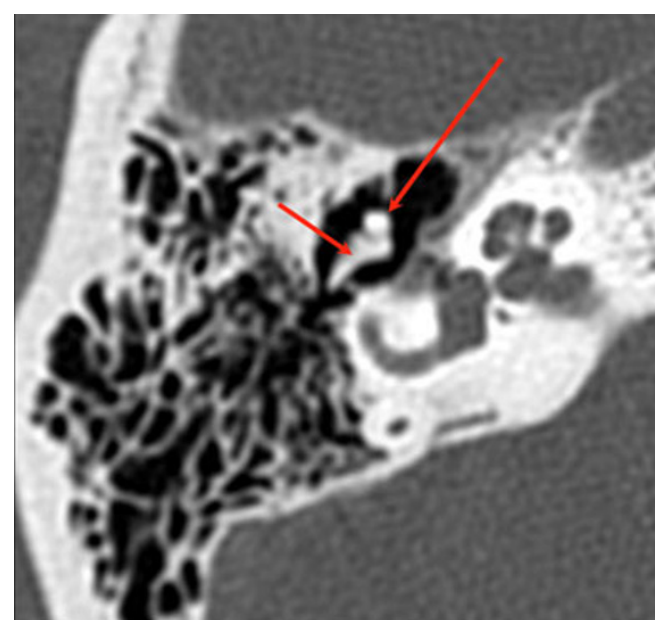

Fig. 21 Normal anatomy of middle ear. Axial CT, bone window. Malleus head (long arrow) and incus body (short arrow) with short process are visible in epitympanum, forming a so-called "ice cream cone"

Symptoms Those symptoms typical for cholesteatoma include painless otorrhea, persistent or frequently recurrent in spite of aggressive antibiotic treatment, conductive hearing loss, rarely vertigo.

Treatment Solely surgical. Surgery is usually performed with canal wall up tympanoplasty, where the wall of external auditory canal is preserved, and sometimes canal wall down procedure, when the wall of external auditory canal is removed and large mastoid cavity is left [24, 2628]. Detailed description of these two methods, their advantages and disadvantages are beyond the scope of this review.

Preferable imaging method The preferable imaging method depends on the type of cholesteatoma. Differentiation

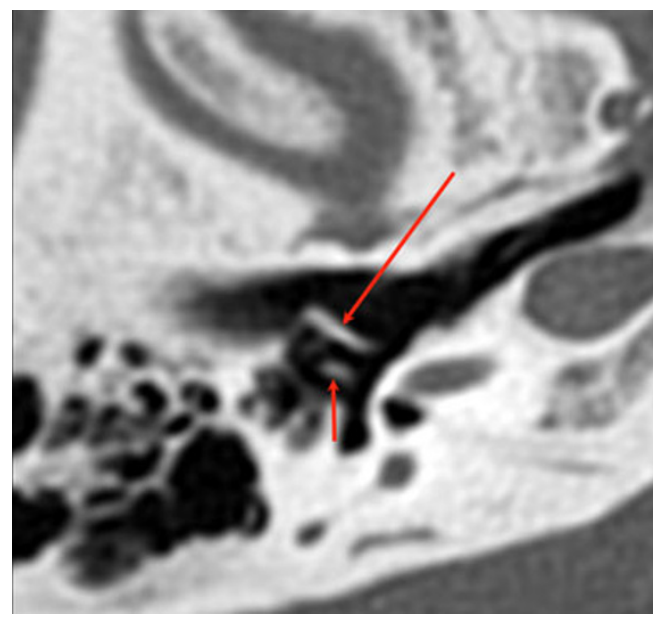

Fig. 22 Normal anatomy of middle ear. Axial CT, bone window. Malleus handle (long arrow) and incus long process (short arrow) are visible, forming two parallel lines

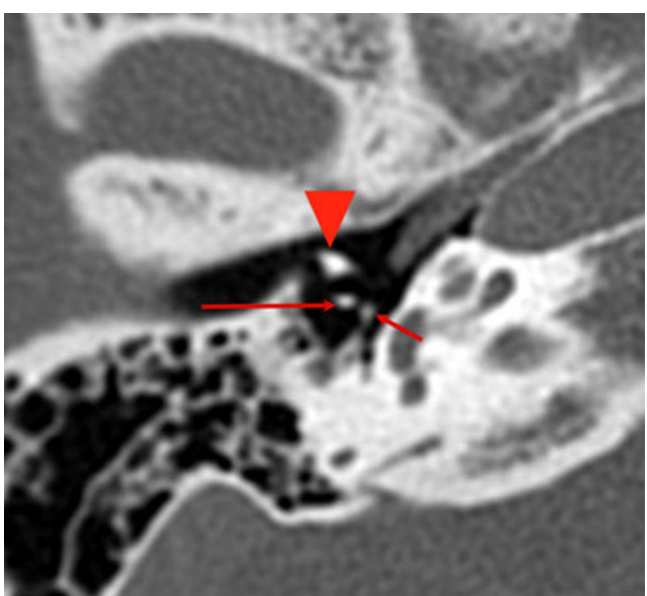

Fig. 23 Normal anatomy of the middle ear. Axial CT, bone window. Two dots, visible posteriorly to malleus neck (arrowhead) represent incus lenticular process (long arrow) and stapes head (short arrow)

should be made between patient evaluation prior to first stage surgery and patient evaluation prior to second-stage surgery looking for residual cholesteatoma. Both imaging techniques - CT and MRI - are valuable but the choice depends on the clinical situation.

Clinically relevant imaging findings Typical cholesteatoma features, visible on CT images, include:

\section{Pars flaccida cholesteatoma:}

soft tissue mass in Prussak's space, medial to attic wall, lateral to head of malleus and body of incus, often accompanied by scutum and ossicle erosionmost commonly long process of incus (Fig. 25a, b). Ossicles are very often displaced medially.

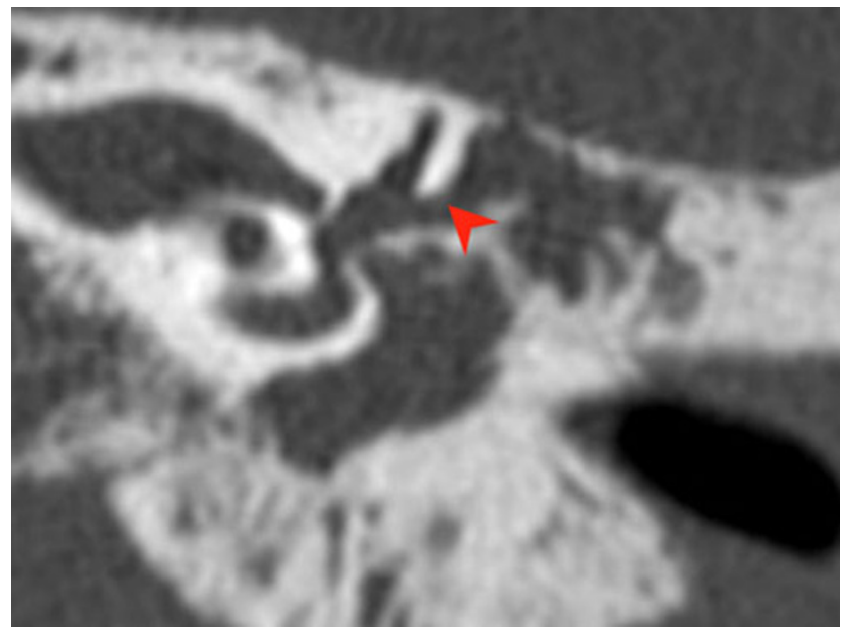

Fig. 24 Chronic middle ear inflammation with cholesteatoma. Coronal CT scan demonstrates lateral semicircular canal fistula (arrowhead), caused by erosion of bone covering the canal due to growing cholesteatoma 


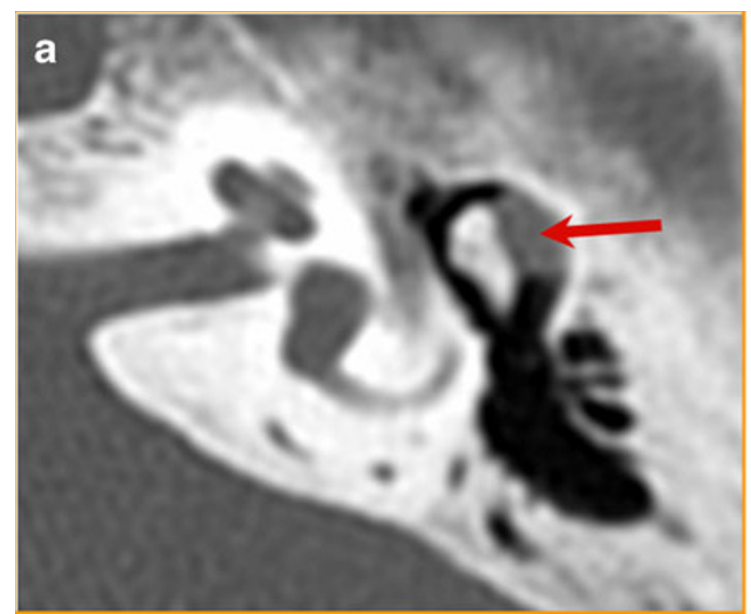

Fig. 25 Chronic middle ear inflammation with cholesteatoma. a Axial CT scan, bone window. Lobulated soft tissue mass is visible laterally to ossicular chain (arrow). b Coronal CT scan: erosion of scutum is

Pars tensa cholesteatoma:

erosive mass of soft tissue density in posterior tympanum, medial to ossicles, may involve sinus tympani, facial recess, mastoid (Fig. 26). Early ossicle erosion is usually present (incus long process, stapedial superstructure, manubrium of malleus). Ossicles can be displaced laterally.

When evaluating CT images for the presence of cholesteatoma, the following features should be addressed:

- Ossicle erosion and displacement

- Bony cover of tegmen tympani and lateral semicircular canal

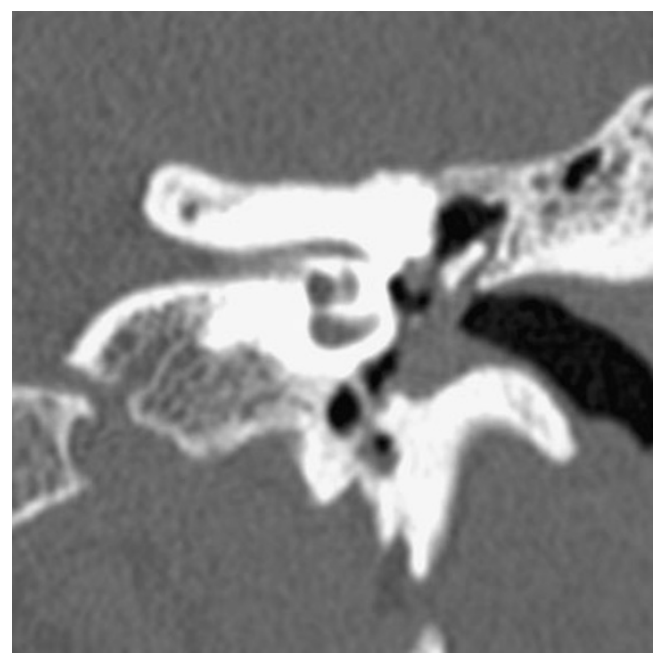

Fig. 26 Chronic middle ear inflammation with cholesteatoma. Axial CT scan shows typical pars tensa cholesteatoma growing medially to ossicular chain

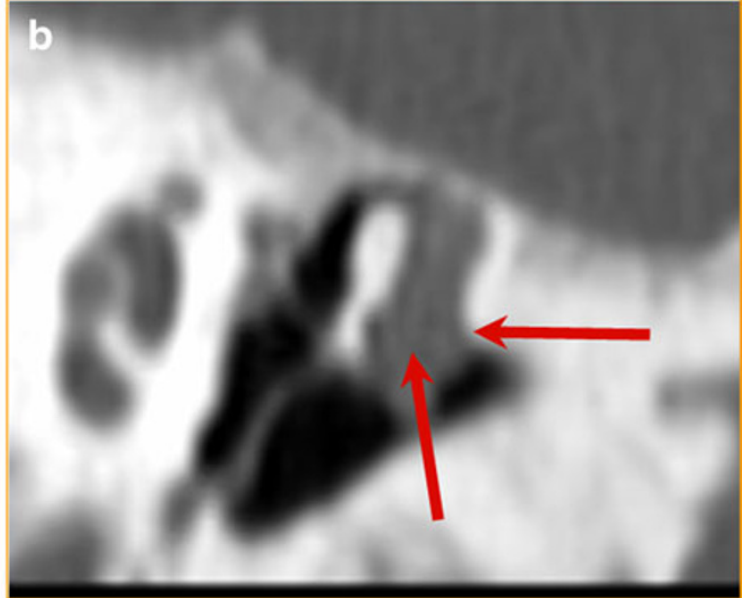

well visible (arrow). The second arrow points at cholesteatoma, growing typically in Prussak's space

- Bony walls of tympanic segment and anterior genu of the facial nerve

- Possible extension of cholesteatoma towards sinus tympani (since it correlates with high post-surgical recurrence rate)

- Possible involvement of oval window niche

Typical cholesteatoma features, visible on MR images, include:

- Bright, hyper-intense signal on B-1,000 images, on diffusion-weighted MRI images (Fig. 27)

- Hypo-intense signal on ADC map

- Lack of enhancement on post-gadolinium T1-weighted sequences

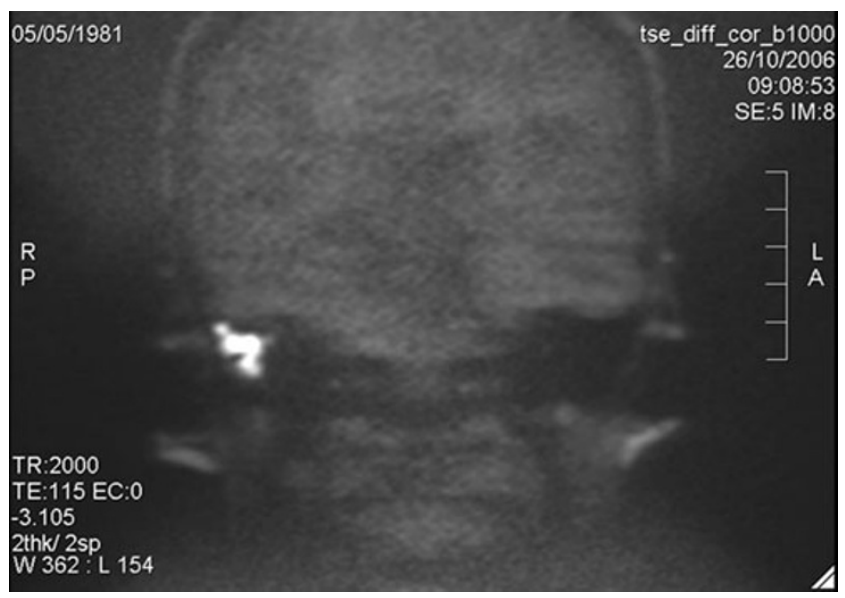

Fig. 27 Chronic middle ear inflammation with cholesteatoma. MRI coronal image, diffusion-weighted sequence (B 1,000). The image shows a hyperintense mass in middle ear cavity representing cholesteatoma. Case courtesy of Dr Bert De Foer, Department of Radiology, AZ Sint-Augustinus, Wilrijk, Belgium 


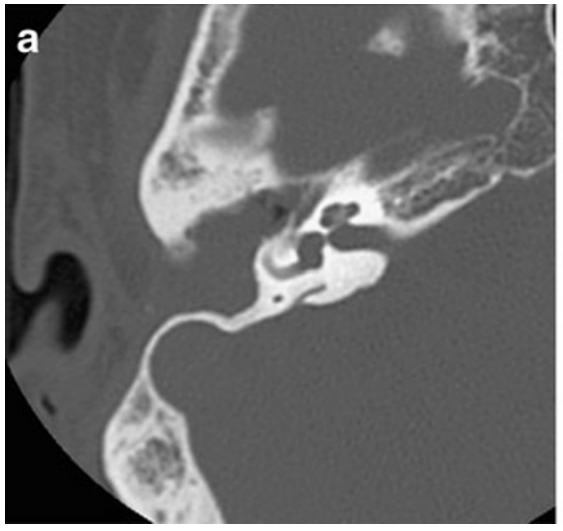

Fig. 28 Postoperative middle ear suspected for cholesteatoma recurrence. a Axian CT scan, bone window, demonstrates diffuse opacification of middle ear cavity. b MRI coronal image. On this nonEPI diffusion-weighted sequence a small hyperintense point is visible

Moderate intensity on T2-weighted images, clearly lower than the hyperintensity of inflammation.

In case of a clear-cut clinical and otoscopical image of a cholesteatoma, CT will do as primary and sole imaging technique prior to first-stage surgery. It will be able to demonstrate ossicular and epitympanic erosion and will nicely show tegmen delineation. Facial nerve canal and lateral semicircular canal integrity can be evaluated as well.

However, in case of suspected infection/inflammation and/or complications such as fistulisation to the lateral semicircular canal, MRI including delayed post-gadolinium T1-weighted sequences and non-echo planar diffusionweighted (non-EP DWI) sequences is required. It will be able to differentiate the infection/inflammation from the cholesteatoma and it will show the status of the membranous labyrinth.

In case of an unequivocal clinical suspicion of cholesteatoma, non-EP DWI sequence alone can be used as a screenings tool to exclude the presence of cholesteatoma. The approach, however, becomes completely different in patient evaluation prior to second look. In these cases, CT cannot distinguish between different types of soft tissues in

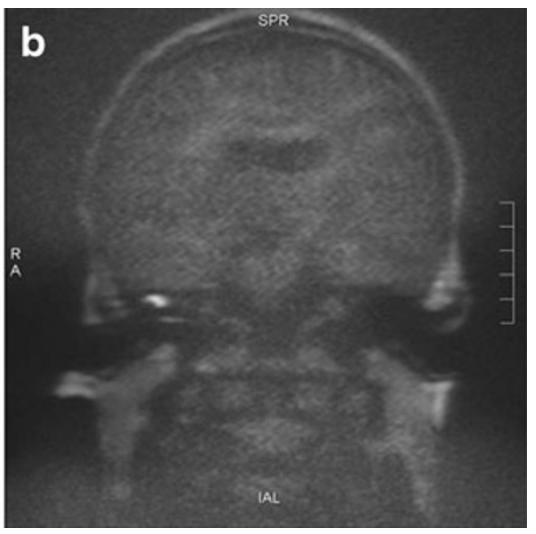

under the tegmen tympani (B 1,000 image), which represents residual cholesteatoma. Case courtesy of Dr Bert De Foer, Department of Radiology, AZ Sint-Augustinus, Wilrijk, Belgium

the resection cavity (granulation tissue, effusion, scar tissue or cholesteatoma). CT has a high negative predictive value only in a well aerated middle ear and post-operative cavity. However, this is seldom seen. In the literature, two MRI techniques have been described for the evaluation of pre second look patients: delayed post-gadolinium T1-weighted sequences and diffusion-weighted MRI (EPI as well as nonEPI) or a combination of both techniques. Non-EPI is regarded as far superior to EPI.

Using the combination of non-EP DW sequences and delayed post-gadolinium sequences, a high sensitivity $(90 \%)$ and specificity $(100 \%)$ was achieved in detection of residual and recurrent cholesteatoma. Recent literature has also demonstrated that non-EP DWI sequences alone have the same sensitivity, specificity, positive predictive value and negative predictive value that the combination of non-EP DWI plus delayed post-gadolinium T1-weighted sequences together (Fig. 28a, b) [28].

So, non-EPI sequences can be used alone in pre-secondlook patients as a screening tool avoiding the need of delayed post-gadolinium T1-weighted sequences. In this setting, CT scan is preserved for the immediate pre-
Fig. 29 Glomus tympanicum paraganglioma. a Coronal CT scan with no contrast enhancement demonstrates a small oval soft tissue mass (arrow) on cochlear promontory. b Axial CT scan shows small glomus tympanicum in typical location (arrow)
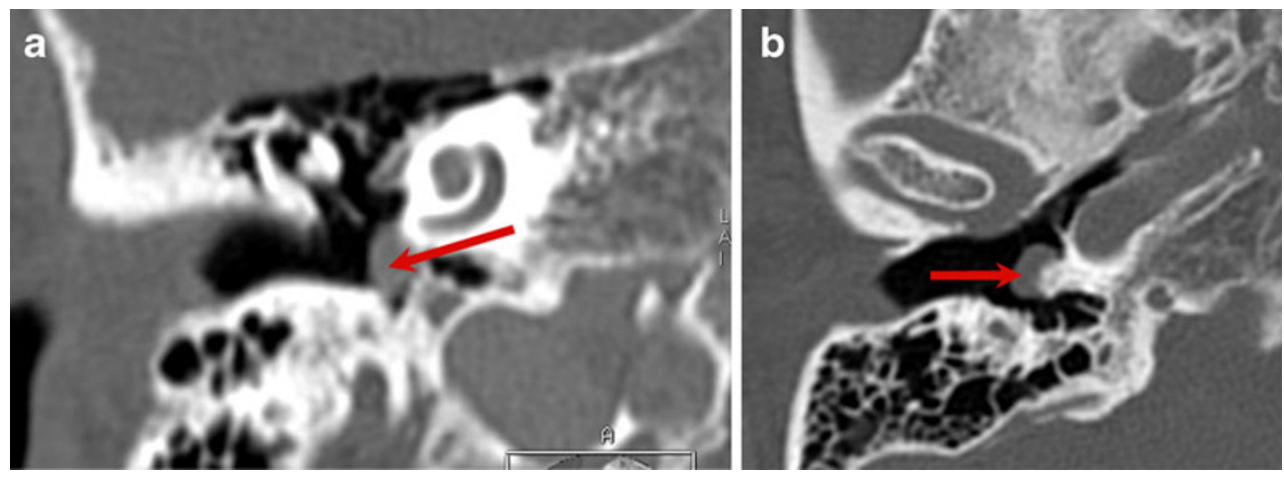


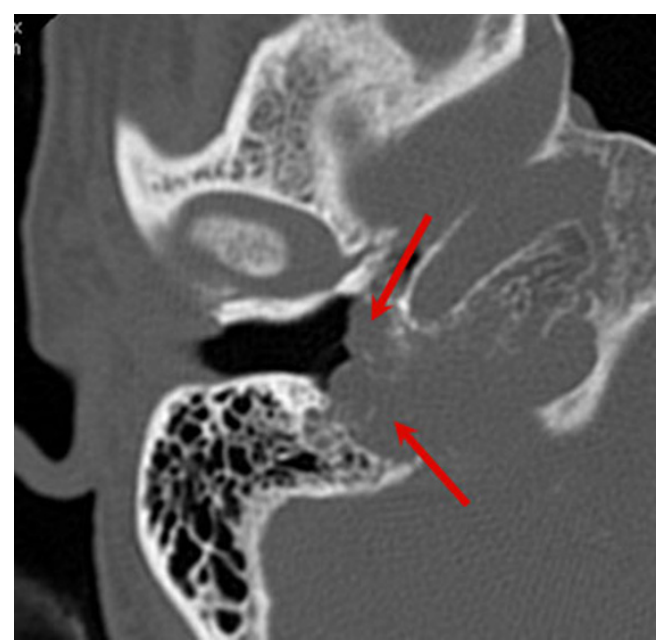

Fig. 30 Glomus jugulotympanicum. Axial CT scan in bone window shows opacification in tympanic cavity and destruction of mastoid air cells, caused by glomus jugulotympanicum (arrows)

operative setting in order to see local temporal bone anatomy

Non-traumatic opacified middle ear: glomus tympanicum paraganglioma (GTP)

Definition Paraganglioma that arises in glomus bodies situated in the cochlear promontory. It is the most common primary neoplasm of the middle ear [29].

Symptoms When growing typically lateral to the cochlear promontory, may abut the inner margin of the tympanic membrane, and present with conductive hearing loss and a red, pulsatile, vascular retrotympanic mass. Other clinical symptoms include pulsatile tinnitus and, rarely, facial nerve paralysis [29, 30].

Preferable imaging method HRCT should be the examination of choice, if GTP is clinically suspected. In other settings a thin-slice CT before and after contrast provides the diagnosis. MRI is used, if based on CT findings glomus jugulotympanicum is suspected.

Clinically relevant imaging findings: on CT images GTP presents typically as a soft-tissue mass, with a flat base on cochlear promontory, vividly and quickly enhancing after

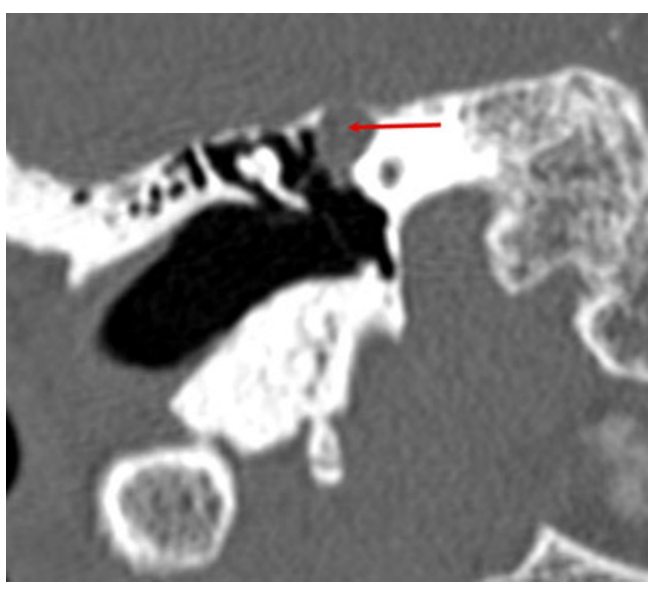

Fig. 31 Facial nerve schwannoma. Axial CT image, bone window, demonstrates widening of geniculate ganglion, where homogenous, soft tissue mass is present, representing schwannoma of the 7th nerve (arrow)

contrast medium administration (Fig. 29a, b). Large GTP can fill whole middle ear cavity; this could result in fluid collection in mastoid. The floor of the middle ear cavity should be intact-if dehiscent or permeative, glomus jugulotympanicum should be suspected (Fig. 30). Very large GTP may show so-called "aggressive" bone changes - eroding the medial wall of the middle ear cavity and ossicles.

For the most efficient communication with ENT surgeons, GTP should be evaluated according to Glasscock-Jackson classification [31] (Table 4).

Differential diagnosis includes aberrant internal carotid artery, dehiscent jugular bulb, glomus jugulotympanicum paraganglioma, facial nerve schwannoma from tympanic segment.

Treatment is solely surgical, but in elderly patients may not be necessary, since GTP grows very slowly.

Non-traumatic opacified middle ear: middle ear schwannoma

Definition tumour arising within middle ear cavity, originating from the facial nerve, chorda tympani nerve ( 7 th branch), Jacobson nerve (9th branch), or Arnold nerve
Table 4 Glasscock-Jackson classification of GTP

\begin{tabular}{ll}
\hline Type & Description \\
Type I & Small mass limited to cochlear promontory \\
Type II & Tumour completely filling middle ear space \\
Type III & Tumour filling middle ear and extending into mastoid air cells \\
Type IV & Tumour filling middle ear, extending into mastoid air cells or through \\
& Tympanic membrane to fill external auditory canal; may extend anteriorly to the carotid artery
\end{tabular}


(10th branch), with the facial nerve being the most common nerve of origin.

Schwannomas have been identified along the entire course of the facial nerve, although intratemporal tumours appear to be much more common than intracranial tumours. Within the temporal bone, the most common sites of involvement, in descending order, are the geniculate ganglion, labyrinthine segment, tympanic and vertical segments, and the internal auditory canal [32].

Symptoms Clinically middle ear schwannomas present with conductive hearing loss and sometimes with facial nerve dysfunction. On otoscopy they are visible as fleshy-white mass behind intact tympanic membrane.

Preferable imaging method MRI before and after contrast enhancement.

Clinically relevant imaging findings Schwannoma is isointense or hypointense on T1-weighted images, hyperintense on T2-weighted images, and markedly enhances with gadolinium contrast. An enhancing enlargement of varying thickness along a large segment of facial nerve is considered highly suggestive of schwannoma. Although high-resolution CT scanning can reveal these tumours because of their osseous erosion and enlargement of facial nerve canal (Fig. 31), MRI is a more sensitive diagnostic tool [8, 32]. However, both modalities are useful for surgical planning.

Middle ear schwannoma, when not originating from 7th nerve, is seen within middle ear cavity as a well-marginated mass without facial canal involvement.

Differential diagnosis includes congenital cholesteatoma, glomus tympanicum paraganglioma, middle ear adenoma.

\section{Conclusions}

Many diseases of the external and middle ear are difficult to recognize and evaluate based on radiological images only, without knowledge concerning clinical symptoms and otoscopy findings. Apprehension of the clinical picture facilitates radiological investigation, substantially narrows differential diagnosis and helps avoid mistakes [33].

Many pathological conditions of the external and middle ear do not require diagnostic imaging; the need for imaging comes when complications are suspected or treatment is not effective. Evaluation of such cases requires close cooperation between the clinician and radiologist.

When malignancy is suspected or surgery is the treatment option, radiological report should include practical information necessary for the surgeon; this can be achieved by using international grading systems or classifications.
Acknowledgements The authors are very grateful to Dr Bert De Foer, from Department of Radiology, GZA Hospitals Sint-Augustinus, Antwerp, Belgium, for expert advice concerning cholesteatoma imaging and permission to use examples of non-EPI DW images.

Open Access This article is distributed under the terms of the Creative Commons Attribution Noncommercial License which permits any noncommercial use, distribution, and reproduction in any medium, provided the original author(s) and source are credited.

\section{References}

1. Zielhuis GA, Rach GH, Van den Bosch A, Van den Broek P (1990) The prevalence of otitis media with effusion: a critical review of the literature. Clin Otolaryngol Allied Sci 15:283-288

2. Williamson I (2006) Otitis media with effusion. Clin Evid $15: 814-821$

3. Birch L, Elbrond O (1997) Prospective epidemiological study of common colds and secretory otitis media. Clin Otolaryngol Allied Sci 12:45-48

4. Harnsberger HR (1995) The temporal bone: external, middle and inner ear segments. In: Gay SM (ed) Handbook of head and neck imaging Mosby, St. Louis 426-458

5. Lemmerling M, De Foer B (2004) Imaging of cholesteatomatous and non-cholesteatomatous middle ear disease. In: Lemmerling M, Kollias SS (eds) Radiology of the petrous bone. Springer, New York, pp 31-47

6. Harnsberger HR (2005) Diagnostic imaging. Head and neck, 1st edn. Amirsys INC

7. Schuknecht HF (1989) Congenital aural atresia. Laryngoscope 99:908-917

8. Ishimoto SI, Ito K, Yamasoba T, Kondo K, Karino S, Takegoshi H, Kaga K (2005) Correlation between microtia and temporal bone malformation evaluated using grading systems. Arch Otolaryngol Head Neck Surg 131:326-329

9. Jahrsdoerfer RA, Yeakley JW, Aguilar EA, Cole RR, Gray LC (1992) Grading system for the selection of patients with congenital aural atresia. Am J Otol 13:6-12

10. Amorosa L, Modugno GC, Pirodda A (1996) Malignant external otitis: review and personal experience. Acta Otolaryngol Suppl 521:1-16

11. Grandis JR, Curtin HD, Yu VL (1995) Necrotizing (malignant) external otitis: Prospective comparison of CT and MR imaging in diagnosis and follow-up. Radiology 196:499504

12. Grandis JR, Branstetter BF IV, Yu VL (2004) The changing face of malignant (necrotising) external otitis: Clinical, radiological, and anatomic correlations. Lancet Infect Dis 4:34-39

13. Wong BJF, Cervantes W, Doyle KJ, Karamzadeh AM, Boys P, Brauel G, Mushtaq E (1999) Prevalence of external auditory canal exostoses in surfers. Arch Otolaryngol Head Neck Surg 125:969972

14. Fenton JE, Turner J, Fagan PA (1996) A histopathologic review of temporal bone exostoses and osteomata. Laryngoscope 106:624-628

15. Pfreundner L, Schwager K, Willner J, Baier K, Bratengeier K, Brunner FX, Flentje M (1999) Carcinoma of the external auditory canal and middle ear. Int $\mathrm{J}$ Radiat Oncol Biol Phys 44:777-788

16. Arriaga M, Curtin H, Hirsch BE, Takahashi H, Kamerer DB (1990) Staging proposal for external auditory meatus carcinoma based on preoperative clinical examination and computed tomography findings. Ann Otol Rhinol Laryngol 99:714-721 
17. Lemmerling MM, De Foer B, VandeVyver V, Vercruysse J-P, Verstraete KL (2008) Imaging of the opacified middle ear. Eur J Radiol 66:363-371)

18. Cannon CR, Jahrsdoerfer RA (1983) Temporal bone fractures: review of 90 cases. Arch Otolaryngol 109:285-291

19. Ishman SL, Friedland DR (2004) Temporal bone fractures: Traditional classification and clinical relevance. Laryngoscope 114:1734-1739

20. Dahiya R, Keller JD, Litofsky NS (1999) Temporal bone fractures: Otic capsule sparing versus otic capsule violating; clinical and radiographic considerations. J Trauma 47:1079-1085

21. Sadé J, Russo E, Fuchs C, Cohen D (2003) Is secretory otitis media a single disease entity? Ann Otol Rhinol Laryngol 112:342-347

22. Manolidis S, Pappas D, Von Doersten P (1998) Temporal bone and lateral skull base malignancy: experience and results with 81 patients. Am J Otol 19:S1-S15

23. Swartz JD (1984) Cholesteatomas of the middle ear: diagnosis, etiology and complications. Radiol Clin North Am 22:15-35

24. Vercruysse JP, De Foer B, Somers T, Casselman J, Offeciers E (2009) Magnetic resonance imaging of cholesteatoma: an update. B-ENT 5:233-40

25. Swartz JD, Wolfson RJ Marlowe FI (1985) Postinflammatory ossicular fixation: CT analysis with surgical correlation. Radiology $154: 697-700$
26. Vercruysse P, De Foer B, Pouillon M (2006) The value of diffusion-weighted MR imaging in the diagnosis of primary acquired and residual cholesteatoma: a surgical verified study of 100 patients. Eur Radiol 16:1461-1467

27. De Foer B, Vercruysse JP, Pilet B (2006) Single-shot, turbo spin-echo, diffusion- weighted imaging versus spin-echoplanar, diffusion-weighted imaging in the detection of acquired middle ear cholesteatoma. AJNR Am J Neuroradiol 27:1480-1482

28. De Foer B, Vercruysse JP, Spaepen M (2010) Diffusion-weighted magnetic resonance imaging of the temporal bone. Neuroradiology 52:785-807

29. Cheesman AD (1997) Glomus and other tumours of the ear. Otology 3:1-16

30. Jackson CG (2001) Glomus tympanicum and glomus jugulare tumors. Otolaryngol Clin North Am 34:941-970

31. Alaani A, Chavda SV, Irving RM (2009) The crucial role of Imaging in determining the approach to glomus tympanicum tumors. Eur Arch Otorhinolaryngol 266:827-831

32. Saleh E, Achilli V, Naguib M, Taibah AK, Russo A, Sanna M, Mazzoni A (1995) Facial nerve neuromas: diagnosis and management. Am J Otol 16:521-526

33. Devaney KO, Boschman CR, Willard SC, Ferlito A, Rinaldo A (2005) Tumours of the external ear and temporal bone. Lancet Oncol 6:411-420 